\title{
El cartel, cuerpo analizante en el campo laico-niano'
}

\author{
Matías Buttini
}

\begin{abstract}
Resumen
¿Qué vigencia tienen los dispositivos propuestos por Lacan? ¿Cómo se ejercen hoy en día en el campo lacaniano, campo del goce? Este campo, que necesita de los cuerpos y de sus resonancias, lo hemos denominado con un equívoco de la lengua española para señalar su no-religiosidad: campo laico-niano. Situaremos el trabajo de carteles tomado en dos aspectos: el de la abstinencia del Más Uno y el del cuerpo analizante.
\end{abstract}

\section{Palabras clave:}

Resonancia; Campo; Cartel; Escuela.

\section{The cartel, analyzing body in the laic-nian field}

\begin{abstract}
What is the validity of the devices proposed by Lacan? How are they practiced today in the Lacanian field, the field of enjoyment? This field, which needs the bodies and their resonances, we have called it from a misunderstanding over the Spanish language to indicate its non-religiosity: the laic-anian field. There we will place the work of cartels taken in two aspects: that of the abstinence of the Plus One and the analyzing body.
\end{abstract}

\section{Keywords:}

Resonance; Lacanian field; Cartel; School.

\footnotetext{
1 La presente texto reúne dos ponencias breves originalmente presentadas en dos Jornadas anuales de carteles EPFCL-ALSur en 2016 y en 2017. Nos pareció un trabajo continuo que merecía estar publicado en su conjunto. Se intentó mantener el carácter coloquial, estilo más cercano a lo particular del cartel que a la Uni-versidad, Uno versión de lo universal.
} 


\section{0 cartel, corpo analisante no campo laico-niano}

\section{Resumo}

Quão válidos são os dispositivos propostos por Lacan? Como se exerce hoje, no campo lacaniano, o campo do gozo? Esse campo, que necessita dos corpos e de suas ressonâncias, nós o chamamos a partir de um equívoco da língua espanhola para indicar sua não religiosidade: o campo laico-niano. Vamos colocar o trabalho dos cartéis em dois aspectos: o da abstinência do Mais-Um e o do corpo analisante.

\section{Palavras-chave:}

Ressonância; Campo; Cartel; Escola.

\section{Le cartel, corps d'analyse dans le champ laïque-nien}

\section{Résumé}

Quelle est la validité des dispositifs proposés par Lacan ? Comment s'exercent-ils aujourd'hui dans le champ lacanien, le champ de la jouissance ? Ce champ, qui a besoin des corps et de leurs résonances, nous l'appelons champ laïque-nien, à partir d'une équivoque de la langue espagnole, pour indiquer sa non-religiosité. Nous placerons le travail des cartels sous deux aspects : celui de l'abstinence du Plus-Un et celui du corps analysant.

\section{Mots-clés :}

Résonance ; Champ ; Cartel ; École. 


\section{Primera parte: La abstinencia del Uno más}

Quisiera presentar una idea que se nos ha aparecido en conversación con Fernando Martínez. A ello le voy a agregar algunos puntos de reflexión, algo propio del trabajo de un cartel si seguimos la etimología del término, re-flectus, o sea, volver a flexionarnos, a doblarnos un poco, al modo de una torsión de apertura a la palabra del otro, colega, sin que ello implique lo homo sumisión, sino más bien, lo hétero, lo diferente.

La idea surgió respecto de la participación de cada uno, en diferentes carteles a lo largo del tiempo. La formulo de dos maneras:

1. Respecto de la función freudiana de la abstinencia, ¿cómo se pone en juego el deseo del analista en un cartel?

2. En relación a "el cuerpo en análisis", significante producido como título de un cartel que comenzó a funcionar a fin del 2015 vía Skype, lo que permite salvar las distancias. Algunos nos estamos viendo en "carne y hueso" por primera vez hoy, en esta reunión. La pregunta podría plantearla así: ¿cómo se pone el cuerpo en un cartel? O de forma más extensiva, ¿cómo se pone el cuerpo en una Escuela, o como se hace cuerpo en el campo lacaniano?

Tomemos el sintagma que usamos hace ya algunos años para presentar el seminario fundamental, el punto reflexivo, de encuentro entre el Foro y la Escuela en el FARP, Ética y política del campo lacaniano, y pongámoslo a trabajar. ¿Cuál es la ética y la política del cartel?

Absteniéndome, desde ya, del juicio que implicaría decir algo sobre cómo cada uno se gana la vida con el psicoanálisis y sus seudópodos transferenciales, quiero situar que encuentro un problema en la idea de los "grupos de estudio", ${ }^{2}$ en su oposición radical al trabajo promovido por un cartel y por ende, al trabajo que se realiza en una Escuela.

Si abordamos la cuestión desde el lado del narcisismo, entiendo que puede hacer sentir bien que el nombre propio sea un significante al que alguien se dirige con un pedido. Ese sería un pedido en relación al saber del psicoanalista, el saber acumulado por la experiencia o mejor aún, la suposición de saber que no lleva necesariamente a un análisis. Psicoanálisis en extensión, diríamos casi automáticamente. Allí no hay mucho espacio para el encuentro entre el narcisismo de las pequeñas diferencias, porque eso suele funcionar como un "ese dos", ese otro al que uno le dirige su demanda de amor: quiero saber más sobre ese ágalma que representas para mí. Sea que el que agrupa estudiantes alrededor de su nombre o del de un tema o autor, se ubique del lado de responder a la demanda o del lado de

2 Formato ampliamente utilizado en Argentina, donde un grupo de noveles analistas se reúne en derredor de un "sabio" para leer cierto seminario o texto. 
abstenerse, el lugar del saber supuesto quedaría intacto. Sin cuestionamientos o más precisamente, in-tocado. Allí el hay uno que sabe, como dice Lacan solamente refiriéndose a Freud, haría consistencia, incluso encarnación real. No hay acá nada cercano a la Escuela, al menos no a la que querríamos proponer en nuestro campo. Recordemos que Lacan, en El acto analítico sostiene:

(...) yo no soy profesor porque justamente cuestiono al sujeto supuesto al saber. Es justamente lo que el profesor no cuestiona jamás puesto que esencialmente él es, en tanto que profesor, su representante. (Lacan, 1967-1968, clase del 28 de enero de 1968)

\section{El grupo no es el cartel}

Aunque éste sea un pequeño grupo, con las dos apoyaturas que lo constituyen (Lacan, 1964/2008-2010), , ${ }^{3}$ no avala la identificación, o al menos debe poder ponerla en cuestión. Si tomamos dos referencias no al cartel sino a la paranoia, o lo que hace consistir más que otras posiciones el goce del Otro, tenemos que por un lado, la disolución periódica implica conmover el posible "pegoteo imaginario" y hasta evitar caer en el congelamiento del deseo (Lacan, 1975-1976, clase del 8 de abril de 1975; Buttini, 2016b); por el otro, el trabajo mancomunado se opone a la producción que se espera que sea individual, a título propio.

El cartel, a diferencia de cualquier grupo, funcionando como órgano de la Escuela permite prestar $a$-tensión, advertir la diferencia entre el trabajo de sentido común y la producción individual. El cartel no elude las identificaciones de todo grupo humano, pero pone en primer lugar la paridad y no el Ese Uno. Me gusta como lo dice Colette Soler, en el ámbito de la Escuela el juez es el texto de Freud y de Lacan.

Por otro lado, el cartel toma otra forma de la demanda, Lacan la llamó transferencia de trabajo, reverso del trabajo de transferencia, pluralizada. Esta inversión, como guante dado vuelta, habilitaría lugares muy diferentes en cuanto a relación entre saber, Escuela y esos unos que la componen. Una Escuelanalizante, holofrase que ya utilicé alguna vez (Buttini, 2011), implica la descomposición analítica en el interior de otro lazo (Buttini, 2016a). Ana-lysis, ruptura de los lazos en el interior de otro lazo. El cartel, nuevamente, se apoya en un discurso destinado a su disolución con la esperanza de producir un trabajo de transferencia en el marco de la Escuela. Así podemos concebirlo como dispositivo intermedio entre el pase y el análisis. La Escuela es cuerpo hablante.

Si el llamado Más Uno logra poner ese lugar de supuesto saber al que puede ser convocado en cuestión, ello habilitará a los otros integrantes a ubicarse como

3 El número de entre tres y cuatro más uno y la permutación. 
unos sueltos, reunidos en acto pero no macerados ni indistintos por cualquier ideal. No hacen un solo cuerpo, sino un encuentro de cuerpos. Organización circular, dice Lacan y no jerarquía (Lacan, 1964/2008-2010, p. 260). ${ }^{4}$

La figura del Más Uno, recordemos, es el encargado de "la selección, discusión y destino que se reservará a cada uno"; aunque no constituirá, sin embargo, "un cacicazgo, cuyo servicio una vez prestado se capitalizaría para el acceso a un grado superior" (Lacan, 1964/2008-2010).

Los caciques se diluyen fuera de sus tribus, en el refugio de voces singulares que promueve la Escuela, en ese trabajo cuyo objetivo es, dice Lacan, "indisoluble de una formación que ha de dispensarse en ese movimiento de reconquista" (Lacan, 1964/2008-2010).

Esta reconquista del campo del psicoanálisis, llevada adelante por unos sueltos y no por caciques, se sostiene en "proscribir" la vida de grupo que "preserva la institución llamada internacional" (Lacan, 1972/1984, p. 46) - dirá en El Atolondradicho -, con el equívoco que se escucha en ese preservar: por ello se preserva y preserva ese funcionamiento en su interior. ¿Cómo sostener una Escuela fuera de la pedagogía y la didáctica en el campo no religioso pero sí de lazo entre colegas?

Hay una respuesta de Lacan en ese mismo texto: frente a la imposibilidad de que los psicoanalistas formen grupo, él dice que el discurso psicoanalítico puede precisamente fundar un vínculo social limpio de toda necesidad de grupo (Lacan, 1972/1984).

Entonces, si entendemos la abstinencia, ${ }^{5}$ como una versión freudiana de la función deseo del analista, podemos decir que la abstinencia del más uno que proponemos es el plus que puede situar las cosas de otra forma, en planos diferentes al del grupo de estudio:

1. No se paga por el saber con dinero.

2. No hay un "ese dos", constituido en el lugar del Otro al que se dirige una demanda de saber sino una circularidad reversible al modo moebiano con la Escuela.

3. Allí no se espera - como en el análisis y la suposición de saber - la promesa de obtener aquello de lo que uno carece o de desembarazarse de lo que uno cree que le sobra.

4. Allí - no siempre sucede, por eso uso el potencial - puede haber encuentro entre colegas y una transferencia de trabajo, transferir en el sentido más original del término, el que Freud usa en primer lugar en la Traumdeutung, desplazamiento y entonces, movimiento del saber.

\footnotetext{
4 Contrastadas ambas traducciones del mismo texto, hemos optado por la de nuestro Anuario IF-EPFCL por ser más clara en su enunciación y un tanto menos rebuscada que la que se encuentra en Otros escritos (Buenos Aires: Paidós, 2012).

5 Malentendida usualmente como enmudecer o hacerse el muerto, sin que ni Freud ni Lacan indiquen que se trata del caudal de palabras que sale o no de la boca del analista.
} 
Ese más uno, invertido, es uno más... si se abstiene de usar una posición jerárquica que tornaría todo un grupo de estudio con apariencia de cartel "ad honorem", por el honor y el prestigio, por la satisfacción personal y no "ad libitum", por el deseo. Específicamente, por el deseo del analista, ese que no busca el podio propio (o el escabel) sino el decir uno, el Uno-decir (Soler, 2016/2017) del analizante, lo que no concuerda ni tiene porqué concordar con la idea que ese analista se haga sobre ese paciente. Ese decir sobre lo uno, muy diferente a encarnar el Uno, puede trocar a ese Más uno en el cartel en uno más, colega que no por ello deja de asumir sus funciones de Escuela: promover la discusión sin hacer de ese saber un cuerpo sino solamente producción a la hora de permutar. En una conferencia del año 1967, Lacan habla de los psicoanalistas como cuerpo representado y también del "equipo psicoanalítico", de propaganda y de charlatanería (Lacan, 1967/2007, p. 22).

El más Uno deberá cumplir una función de propiciar el que se diga sin encarnar el cacique ni hacer corpus del conjunto de los psicoanalistas. A diferencia del psicoanálisis donde es necesario sostener el no hay y el no es eso, las masas descriptas por Freud - iglesia y ejército - apuntan a constituir un corpus, cuerpo armado y cuerpo eclesiástico, para nombrar dos ejemplos.

Podemos recurrir a la literatura, para cerrar este primer punto y ubicar allí la función de la abstinencia como la condición del surgimiento de algo inesperado, de un hecho nuevo (Lacan, 1967/2007, p. 18). En un excelente libro, el escritor ítalo-mexicano Fabio Morábito señala que en La metamorfosis de Kafka, asistimos a uno de los momentos geniales de la literatura. Gregorio Samsa se despierta y se confronta con el horror de verse, sa-ver (Aguerre, 2011, p. 255) su cuerpo transformado en bicho y esto abre una nueva puerta. Lo dice así:

Kafka posterga la reacción de horror de Gregorio Samsa, la guarda para sacarla después, en el momento debido, y cuando descubre que no la necesita, se convierte realmente en Kafka. En el humilde cuarto de Praga donde ambienta su historia, Kafka acaba de abrir para la literatura una puerta salvadora, que podemos llamar la supresión del grito. (Morábito, 2014, p. 33 , cursiva nuestra)

Me parece una muy buena descripción de la abstinencia de Kafka como escritor quién, suprimiendo el grito de horror que el cuerpo metamorfoseado produce, nos desplaza, nos transfiere, ese trabajo a los lectores, trabajo motorizado no por un saber ya constituido - como bien señala nuestro epígrafe - sino por la causa/ hiancia del deseo. Esta posición deja al lector en el lugar del trabajo y no del mero estudiante presto a ser adoctrinado por el texto - y sus habituales sacralizaciones -, 
conglomerado con otros del mismo rebaño, por el efecto de grupo con esa obscenidad imaginaria añadida al efecto de discurso (Lacan, 1972/1984, p. 46). Estos dos efectos, deben sopesarse, el uno al otro, dice Lacan.

Hasta aquí, algunos puntos reflexivos sobre la función de la abstinencia que Freud propone para el analista y que acá hemos querido hacer extensiva al Más uno/uno más del cartel, como reversión del cartel. Avancemos...

\section{Segunda parte: Cartel, cuerpo analizante}

Comencé criticando la idea del grupo de estudio como incompatible con nuestra Escuela. En su lugar, no hay duda, el cartel es el dispositivo que permitiría que los dichos se desplacen y no se estanquen. Tal como comentó Colette Soler en octubre de 2017 en el Espacio Escuela del FARP (desgrabación inédita), el cartel es el verdadero dispositivo de Escuela porque la transferencia de trabajo circula y no está necesariamente orientada ni fijada.

\section{Campo laico-niano}

Nuestra carta de la IF-EPFCL, ${ }^{6}$ instrumento vivo que ordena nuestros foros y la Escuela, retoma el sintagma campo lacaniano, propuesto por Lacan en términos de su deseo: "por lo que se refiere al campo del goce - por desgracia, nunca lo llamarán el campo lacaniano, porque seguramente no tendré tiempo ni siquiera de sentar sus bases, pero lo he deseado" (Lacan, 1969-1970/1992, p. 86). La carta lo nombra y lo pone en marcha en base a dos principios rectores: el principio de solidaridad y el principio de iniciativa. Ambos se anudan de una manera particular para constituir los límites de nuestra Escuela inscripta allí.

Ese campo, llamado así lacaniano, o si equivocamos el español, laico-niano, es donde el trabajo se lleva a cabo sin religión ni creencia más que en lo que Freud ya nombró existencia del Inconsciente. Lacan, retomando los efectos del decir de Freud sobre la cultura, encuentra necesaria la re-invención del Inconsciente y la creación - sin precedentes - de un campo. Cuáles son los límites de dicho campo, es algo que se ha comenzado a interrogar en vistas de nuestra Cita internacional en Barcelona 2018, sede de la memoria viva de una crisis (Soler et al., 2000) que dio origen al advenimiento de los foros... del campo laico-niano en contra experiencia del campo lacani-Uno. Muchos usan su nombre - el de Lacan para hacerse Uno.

Ahora bien, decir de Freud y deseo de Lacan mediante, aquí estamos en cuerpo presente, una vez más. Los campos y los cuerpos son elementos que permiten un desplazamiento. La pregunta que me hago es la siguiente: ¿qué relaciones hay

6 Recuperado de https://www.champlacanien.net/public/3/ifCharte.php?language=3\&menu=1 
entre un cuerpo y un campo? Y si avanzo un poco más, otro interrogante surge: ¿Podemos decir que el campo del psicoanálisis es un campo donde el cuerpo suena, un campo sonoro?

Daré forma a este comentario en tres breves puntos, pero primero, situemos lo que Pascal Quignard, en su libro El nombre en la punta de la lengua, nos enseña, en una escena crucial de su obra - y de su vida - algo que suena mucho a lo que sucede, a veces, por momentos, en el trabajo de un cartel:

La madre sentada a la mesa con sus hijos, de pronto, "bruscamente nos mandaba a callar". Estaba buscando un nombre que no le salía. "Extraviada, lejana, intentaba, fijo el ojo en nada, centelleante, hacer que le viniera en el silencio la palabra que tenía en la punta de la lengua. Nosotros mismos estábamos en el borde de sus labios. Estábamos al acecho, como ella. La ayudábamos con nuestro silencio - con toda la fuerza de nuestro silencio" (Quignard, 1993/2006, p. 41, cursiva nuestra).

Esa ayuda en silencio puede ilustrar el principio de iniciativa y el principio de solidaridad que rigen nuestros dispositivos: se dirige al otro del lazo y no es simple abstinencia pasiva. El texto citado agrega a continuación: "El nombre en la punta de la lengua nos recuerda que el lenguaje no es en nosotros un acto reflejo. Que no somos bestias que hablan igual que ven" (Quignard, 1993/2006, p. 41).

\section{¿Qué es un campo?}

Esta pregunta coincide con un capítulo del libro de Giorgio Agamben Medios sin fin (Agamben, 1996/2001). Allí se interroga por la existencia de un campo en el ámbito de la política, en la que aún vivimos, dice, y señala una idea que tomaré: el campo se circunscribe surgiendo de la suspensión de las reglas y del todo es posible. ¿Coincide esto con la idea de Lacan? El campo lacaniano, ¿implicaría una anomia? De ninguna manera uno podría responder que sí. Pero, si seguimos a Agamben y sus desarrollos, nos encontramos con un elemento crucial: lo que llama, en términos del derecho romano, el estado de excepción implica el ex-capere, sacado fuera. Una regla fundamental que implica el cuerpo de ese otro analista que es un extraño, alguien por fuera de esa enfermedad, para Freud, huésped mal recibido (Freud, 1905/1991, p. 39) que tiene la posibilidad de responder con su acto que hace excepción a la coherencia, al sentido común y por ello habilita el despliegue del goce, del deseo y del amor.

En El saber del psicoanalista (1971-1972), Lacan retoma su propio título, el de "Función y campo..." para advertir dos cuestiones: por un lado, que ese término ya había sido utilizado por él; por el otro, que dicho campo, lo cito, "está constituido por lo que llamé el otro día con un lapsus: lalengua” (Lacan, 1971-1972, clase del 2 de diciembre de 1971, p. 40, inédito). Entre el diccionario Lalande y el laleo 
del bebé, en el Inconsciente de Jacques Lacan surge lalengua, lapsus que constituye una resonancia de fuerte alcance por estar por fuera del sentido común. Lalengua es aquello que resuena, laica-nianamente hablando, del mismo modo que el goce, lo que sólo puede ser capturado con las orejas y con un cuerpo. En ese espacio de tiempo que va de un texto al otro, está Lacan en posición analizante. Se escucha, resuena y luego, lo elabora.

\section{¿Qué es un cuerpo analizante?}

Si avanzamos por la vía del cuerpo y las resonancias, - tal como lo hicimos en un cartel con los colegas de la Patagonia que evocaba inicialmente sobre el cuerpo en análisis -, nos topamos con algunas cuestiones centrales y con un inmenso campo en el que no entraré hoy. Sólo voy a señalar esta conexión entre el cuerpo y el analizante. Ese es el cuerpo constituido en las paredes resonantes de un análisis, en el consultorio del analista. No es un corpus teórico, sino un corpus en acto de decir, pifiando, errando, demostrando el sin cálculo del Inconsciente. Un cuerpo que espera, tiene "esperanza", dice Colette Soler, del todo puede ser dicho. El límite deberá hacerse audible en la forma de lo in-audito.?

En esas paredes, encontramos una analogía muy antigua con la caverna platónica. Metáfora, como sabemos, de lo perceptivo, aunque no es este cuerpo perceptivo el cuerpo analizante; no es el de los sentidos, sino el que suena en el hilo desparejo de sus dichos asociativos. Esos sentidos corporales son los que el analista, podemos decirlo así, niega o rechaza para privilegiar el concepto de Pulsión. ¿Qué quiere decir esto? Que hay pulsión en juego y que eso, más allá del principio del placer, es lo que se hace escuchar. No son los cinco sentidos sino más bien, los cinco objetos pulsionales los que están en juego en ese espacio del análisis.

Nuevamente Pascal Quignard, lúcido en cuestiones de la voz y la música, señala que las cavernas paleolíticas no eran obras de arte pictórico sino adornos para esos "resonadores nocturnos" (Quignard, 1996/2012, p. 94). Agrega que no se trata de "santuarios de imágenes", como se suele pensar, sino de "cámaras de eco" (Quignard, 1996/2012).

Lacan, también lúcido, nos presenta ésta tesis varios años antes que Quignard, cuando señala su famosa frase del seminario sobre El Sinthome: "las pulsiones son el eco en el cuerpo del hecho de que hay un decir" (Lacan, 1975-1976/2006, p. 18). Allí critica a los "filósofos ingleses" (Lacan, 1975-1976/2006), como llama irónicamente a los psicoanalistas anglófonos, quienes han traducido en Freud Trieb

7 He trabajado sobre este punto y su relación con una Escuela en "Voces desde lo inaudible: verificación, auditoría y pasaje por la Escuela", publicado en Stylus: Revista de Psicanálise, 32, Junio 2016. Se puede encontrar una versión en español en la web del FARP: http://forofarp.org/images/ pdf/Buttini.pdf 
por instinto. Y Lacan añadirá en esa página tres cosas centrales: uno, "es preciso que haya algo en el significante que resuene"; dos, "para que este decir resuene, es preciso que el cuerpo sea sensible a ello"; tres, de los orificios del cuerpo, la oreja es el más importante, dice, porque no puede taponarse o cerrarse.

Está hablando sin duda de lo que denominamos cuerpo analizante, el que está atado al mástil del acto del decir, al igual que Odiseo sujetado a su navío para poder escuchar el canto de las sirenas, figura ineludible los efectos siniestros y sonoros del Inconsciente. Este cuerpo también puede des-atarse del Otro de la escena del mundo en la excitación psicomotriz, la manía o el pasaje al acto, estados que corroboramos en la práctica, y que excluyen, in situ, la intervención de un analista.

¿Cómo entra el cuerpo en el campo lacaniano? Si seguimos a Freud y a Lacan, entra recostado en un diván... lo que no concuerda con la comodidad casi en ningún punto. Entra en el “esp de un laps” (Lacan, 1977/2012), es decir, en el campo de lalengua y aquello que re-suena en el lazo de la transferencia.

\section{¿El cartel puede ser pensado como el decir que pasa a través de la Escuela?}

¿Como hacemos para hermanar (Lacan, 1971-1972/2012, p. 230) el cartel con el campo lacaniano? Porque no se trata de un análisis, pero si de un dispositivo de Escuela, sustentado en el hecho de que ex-siste el psicoanalista y, por ende, un campo es necesario donde tratar las resonancias de esa ex-sistencia. Reparemos en el prefijo que Lacan guiona ex-, lo que implica la xené griega, extranjeridad, el estar por fuera de un todo, ex capere (Agamben, 2003/2005). Esto introduce la función del no todo. ¿Cómo hacer para que el cartel como no todo, sea un resonador de la Escuela?

$\mathrm{Si}$, como indica nuestro título, el cartel es cuerpo analizante, ¿eso quiere decir que los integrantes reciben su propio eco (no hablo de mensaje ni de significantes de la demanda) en forma invertida, o mejor aún, introduciendo una diferencia con el análisis, lo reciben del otro, del colega de la Escuela, (e)colega? ${ }^{8}$

En el trabajo de cartel el cuerpo analizante mueve la producción. El \$ que trabaja es quien guía el interés de cada uno por decantar un decir de los dichos allí producidos. Decir histerizado (\$) que cuestiona la coagulación del Amo saber.

Un eco de mi infancia viene en mi ayuda: niños dispersados por el campo jugando, y de pronto, a la hora indicada, se escuchaba a lo lejos el eco de una campana, nos llamaban a sentarnos a la mesa. Campana hace resonar etimológicamente el campo. La campana del cartel nos alerta de los efectos de grupo, habrá que hacerla sonar, cada vez, tarea que se encarna pero no corresponde exclusivamente al Más Uno. No se trata aquí de la campana de la iglesia, algunas de ellas consti-

8 Aquí se equivocan los términos, en la juntura misma de la lengua española y la francesa, entre Lacan y nosotros: école (escuela), cole (pegamento) y colega. 
tuidas con el hierro fundido de cañones, por ejemplo. Más bien de la idea misma de campana en el sentido sonoro. Se trata de un ideófono, es decir, iedos (propio), phono (sonido). Es un dispositivo que tiene sonido propio, pero que necesita de otro para producirlo, ¡al igual que cualquier formación del Inconsciente!

En cierto punto, un cuerpo al que llamemos analizante es un cuerpo que solo se constituye por un acto mutuo: el nudo entre la escucha y el consentimiento de decir. Es un cuerpo en espera de una revelación. Un cuerpo en suspenso, en suffrance, dirá Lacan.

En cuanto al cartel, se mueve por esa esperanza de revelación, de producción conjunta, motorizado por el rasgo de esos unos. Cuando el cartel produce algo, suena la campana, se constituye como cuerpo analizante, cuerpo sonoro que hace eco, resonancia en el campo de lalengua. En ese punto donde el objeto $a$-nalítico se hace escuchar.

A diferencia de lo escópico (sic. piedra arrojada en el lago que produce "ondas" visibles), el eco de una voz, los ecos que puede producir un decir, requieren de un cuerpo que inscriba, que registre, que marque sobre un vacío, a través de un orificio corporal que haga de vasija o de campana.

Es necesario, y el cartel así lo demuestra, que haya otros cuerpos que producen resonancias que afecten o involucren al campo laico-niano, para que devenga dispositivo de Escuela y no aporte a la Iglesia. No alcanza con llamarlo cartel para que no sea grupo de estudio. La Escuela está entonces, ahí detrás, haciéndose ecos de esos decires en expansión que son los carteles. Expansión sonora del decir, lo que una vez dicho puede perderse o quedar registrado, por el que dice o por otros. Algunos otros...

\section{Final abierto}

Freud legó una obra que Lacan elaboró como "el decir de Freud"; Lacan, por su parte, constituyó un campo. La Escuela es ese campo por donde pasa el decir de Freud, siempre como ex-cepción. Ese pasaje tiene como condición que la Escuela se inscriba en el campo laico-niano como punto de juntura entre el goce tomado por el deseo de psicoanálisis, deseo que, sabemos, no es puro en su emergencia ni en su aplicación (Lacan, 1964/1987, p. 284). Punto éste, donde el Uno que afirma la religión y el dieu-lirio ${ }^{9}$ del cántico $a$-unado de los hermanos no puede hacer consistencia ya que resisten las disparidades como función no todo de la Escuela, evitando ir hacia un campo uni-forme, campo nombrable como lacaniUno.

9 Juego intraducible de palabras que utiliza Lacan donde resuena el delirio de dios o dios-lirio, delirio del Uno y por ello siempre religioso: "La ciencia y la religión van muy bien juntas. Es un dieu-lire" (Lacan, 1979, p. 79). 
¿Podríamos sostener entonces que el cartel, como práctica de un dispositivo en el campo laico-niano, es ese agrupamiento no religioso donde la Escuela re-suena, o sea, vuelve a hacer sonar el decir de Freud como una campana? ¿No será este dispositivo el que hace, de modo diferente que el pase, más personalizado e íntimo, viva a la Escuela?

\section{Referencias bibliográficas}

Agamben, G. (2001). Medios sin fin: notas sobre la política. España: Pre-Textos. (Obra original publicada en 1996)

Agamben, G. (2005). Estado de excepción. Buenos Aires: Adriana Hidalgo. (Obra original publicada en 2003)

Aguerre, C. (2011). Puesta a prueba del deseo. In C. Aguerre. Lo que pasa en el Pase no 2. Colombia: Asociación Foro del Campo Lacaniano de Medellín.

Buttini, M. (2011). La Escuela, un ejercicio de elongación. Plata: Espacio Escuela del FARP. Inédito.

Buttini, M. (2016a). Des-enlaces del analista: ¿de eso se trata?. Hétérité: Revue de Psychanalyse, Enlaces y desenlaces según la clínica psicoanalítica, 12, IF-EPFCL. Recuperado de www.champlacanien.net

Buttini, M. (2016b). Figuras de deidades soberanas das margens e do estrangeiro. Folhetim: o Amor, Signo de que Trocamos de Discurso, XIV(12), Rio de Janeiro: Fórum do Campo Lacaniano do Rio de Janeiro.

Freud, S. (1991). Fragmento de análisis de un caso de histeria. In S. Freud. Obras completas (Vol. VII). Buenos Aires: Amorrortu. (Obra original publicada en 1905)

Lacan, J. (1967-1968). El seminario, libro 15: el acto psicoanalítico (Ricardo Rodríguez Ponte, Trad.). Inédito.

Lacan, J. (1971-1972). El saber del psicoanalista. Conferências en Saint Anne. Inédito.

Lacan, J. (1974-1975). El seminario, libro 22: RSI (Ricardo Rodríguez Ponte, Trad.). Inédito.

Lacan, J. (1979). El seminario, libro 24: l'insu-que-sait de l'une-bévue s'aile à mourre. 17 de mayo de 1979. Buenos Aires: Escuela freudiana de Buenos Aires. Inédito.

Lacan, J. (1984). L'étourdit. Escansión, 1, Buenos Aires: Paidós. (Obra original publicada en 1972)

Lacan, J. (1987). El seminario, libro 11: los cuatro conceptos fundamentales del psicoanálisis. Buenos Aires: Paidós. (Obra original publicada en 1964)

Lacan, J. (1992). El seminario 17: el reverso del psicoanálisis. Buenos Aires: Paidós. (Obra original publicada en 1969-1970) 
Lacan, J. (2006). El seminario 23: el sinthome. Buenos Aires: Paidós. (Obra original publicada en 1975-1976)

Lacan, J. (2007). Lugar, origen y fin de mi enseñanza. In J. Lacan. Mi enseñanza. Buenos Aires: Paidós. (Obra original publicada en 1967)

Lacan, J. (2008-2010). Acta de fundación. In J. Lacan. Directorio de la IF-EPFCL. (Obra original publicada en 1964)

Lacan, J. (2012). El seminario, libro 19: ...o peor. Buenos Aires: Paidós. (Obra original publicada en 1971-1972)

Lacan, J. (2012). Prefacio a la edición inglesa del Seminario 11. In J. Lacan. Otros escritos. Buenos Aires: Paidós. (Obra original publicada en 1977)

Morábito, F. (2014). El idioma materno. Buenos Aires: Gog y Magog.

Quignard, P. (2006). El nombre en la punta de la lengua. Madrid: Arena Libros. (Obra original publicada en 1993)

Quignard, P. (2012). El odio a la música. Buenos Aires: El Cuenco de Platas. (Obra original publicada en 1996)

Soler, C. (2017). Otro Narciso. Buenos Aires: Escabel/FARP. (Obra original publicada en 2016)

VVAA, Soler, C., Soler, L., Silvestre, D., Adam, J. (2000). El psicoanálisis frente al pensamiento único: historia de una crisis singular. Buenos Aires: JVE/Foro Psicoanalítico de Buenos Aires.

Recebido: 15/08/2018

Aprovado: 19/11/2018 